Odour-induced umami - olfactory contribution to umami taste in seaweed extracts (dashi) by sensory interactions

Frøst, Michael Bom; Mouritsen, Ole G.; Hartmann, Anna Loraine; Petersen, Mikael Agerlin; Duelund, Lars

Publication date:

2018

Document license:

CC BY-NC-ND

Citation for published version (APA):

Frøst, M. B., Mouritsen, O. G., Hartmann, A. L., Petersen, M. A., \& Duelund, L. (2018). Odour-induced umami olfactory contribution to umami taste in seaweed extracts (dashi) by sensory interactions. Poster session presented at Eurosense 2018, Verona, Italy. 


\title{
Odour-induced umami - olfactory contribution to umami taste in seaweed extracts (dashi) by sensory interactions
}

\author{
Michael Bom Frøst ${ }^{1}$, Ole Mouritsen ${ }^{1}$, Anna Hartmann¹, Mikael Agerlin Petersen², Lars Duelund ${ }^{3}$ \\ ${ }^{1}$ Smag for Livet Design and Consumer Behaviour, Department of Food Science, University of Copenhagen \\ 2Design and Consumer Behaviour, Dept. of Food Science, University of Copenhagen \\ ${ }^{3}$ Department of Chemical Engineering, Biotechnology and Environmental Technology, University of Southern Denmark
}

\section{Introduction}

Umami is a basic taste. However, chefs and other practitioners often refer to it as a flavour or even an aroma. It indicates that sensory interactions, mainly from aroma perception may affect the gustatory response to realistic food products. Similar sensory interactions between a basic taste and olfactory input have been observed for salt taste, and it has been used as a strategy to decrease salt content in cheese (Lawrence, Salles, Palicki, Septier, Busch \& Thomas-Danguin, 2011).

To investigate if similar sensory interactions occur for umami, we set out to create a realistic set of stimuli. Dashi is a simple basic soup stock that can be made simply by extracting seaweed into hot water (Mouritsen, Williams, Bjerregaard, \& Duelund, 2012). With a diverse set of seaweeds, collected from locations in multiple waters (table 1) we created a sensory diverse set of dashis. With sensory descriptive analysis, it is possible to explore odour-induced umami enhancement by omitting the sense of smell in sensory characterization of the dashis.

\section{Methods:}

Dashis were made from 16 seaweeds (9 different species) collected from locations in 6 different countries, following procedures of Mouritsen, Williams, Bjerregaard \& Duelund (2012). Table 1 gives an overview of the samples Samples were characterised by standard sensory descriptive analysis (with and without olfactory input), HPLC following the procedures of Mouritsen, Duelund, Calleja, \& Frøst (2017) and GC following the procedures of Juhari \& Petersen (2018). Data were analysed by ANOVA (in IBM SPSS 24) for effects of olfactory input and interaction effects between olfactory input and samples. PLSR (Unscrambler) was applied to analyse which aroma compounds may have a positive contribution to umami taste.

\section{Results:}

Main effects of olfactory stimulation was found for the basic tastes umami $(p=0.001)$, sweet $(p=0.017)$, and the flavour roasted $(p=0.01)$, with decreases in intensity when olfactory input is prevented. Similar effects were found for the aftertastes astringent, metallic and fatty. However, odour-induced enhancement, indicated by statistical interactions between olfactory input and samples was only seen for umami $(p=0.018)$ and astringent $(p=0.009)$. For umami, dramatic differences in perceived intensity for a number of products can be observed (Figure 1). Thirteen samples show significant differences in perceived umami taste, as a result of olfactory stimulation. HPLC analysis demonstrated that three samples with high umami intensity had very low glutamate content (table 2). Scrutinizing the aroma compound concentration by GC identifies a set of candidates that can have increased umami (table 2).

\section{Acknowledgments:}

This project is part of the interdisciplinary project Smag for Livet (lit. taste for life) funded by Nordea-fonden.

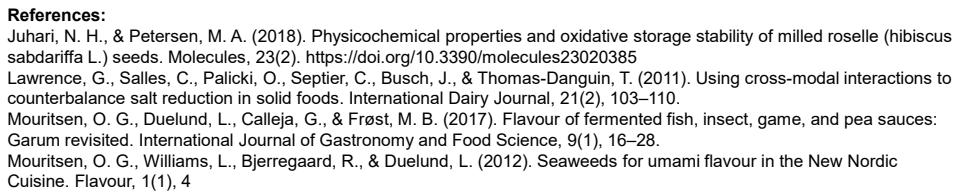

\section{Conclusions}

Sensory interactions between basic tastes and aroma compounds were found in seaweed dashi. Odours that enhance umami were observed in three samples with very low glutamate content. A number of potential odour-induced umami enhancing aroma compounds is suggested (table 2). Odour-induced umami enhancement can be used to create more palatable foods with simple and sustainable means.

\begin{tabular}{|c|c|c|c|}
\hline $\begin{array}{l}\text { Sample abbreviation used } \\
\text { in plots and text }\end{array}$ & Common name & Species & Origin \\
\hline $01 \mathrm{NI}$ & Bull kelp & Nereocystis leutkeana & $\begin{array}{l}\text { Bamfield, Vancouver } \\
\text { Island }\end{array}$ \\
\hline 02Mp & Macrokelp & Macrocystis pyrifera & $\begin{array}{l}\text { Bamfield, Vancouver } \\
\text { Island }\end{array}$ \\
\hline 03Ls & North Pacific konbu & Laminaria setchellii & $\begin{array}{l}\text { Bamfield, Vancouver } \\
\text { Island }\end{array}$ \\
\hline $10 \mathrm{SI}$ & Sugar kelp & Saccharina latissima & Grindavik, Iceland \\
\hline $13 \mathrm{SI}$ & Sugar kelp & Saccharina latissima & Lillebælt, Denmark \\
\hline $15 U p$ & Wakame & Undaria pinnatifida & Brittany, France \\
\hline $16 \mathrm{Ae}$ & Winged kelp & Alaria esculenta & Stykkishólmur, Iceland \\
\hline $18 \mathrm{Sj}$ & $\begin{array}{c}\text { Hidaka-konbu } \\
\text { (Daichu Kahomotsu } \\
\text { Hidaka) }\end{array}$ & Saccharina japonica & Hokkaido, Japan \\
\hline $23 \mathrm{Sj}$ & $\begin{array}{l}\text { Rishiri-konbu } \\
\text { (Fukui district) }\end{array}$ & Saccharina japonica & Hokkaido, Japan \\
\hline $25 \mathrm{Sj}$ & $\begin{array}{l}\text { Raushu-konbu } \\
\text { (Fukuoka) }\end{array}$ & Saccharina japonica & Hokkaido, Japan \\
\hline $26 \mathrm{Sj}$ & $\begin{array}{l}\text { Ma-konbu } \\
\text { (Fukuoka) }\end{array}$ & Saccharina japonica & Hokkaido, Japan \\
\hline $27 \mathrm{Sj}$ & $\begin{array}{l}\text { Ma-konbu } \\
\text { (Sakai) }\end{array}$ & Saccharina japonica & Hokkaido, Japan \\
\hline $28 \mathrm{Pp}$ & Sea palm & Postelsia palmaeformis & California, USA \\
\hline $30 \mathrm{~Eb}$ & Arame & Ecklonia bicyclis & Chiba, Japan \\
\hline $32 \mathrm{Fv}$ & Bladderwrack & Fucus vesiculosus & Lillebælt, Denmark \\
\hline $37 \mathrm{NI}$ & Nereocystis salt & Nereocystis leutkeana & $\begin{array}{l}\text { Bamfield, Vancouver } \\
\text { Island }\end{array}$ \\
\hline
\end{tabular}

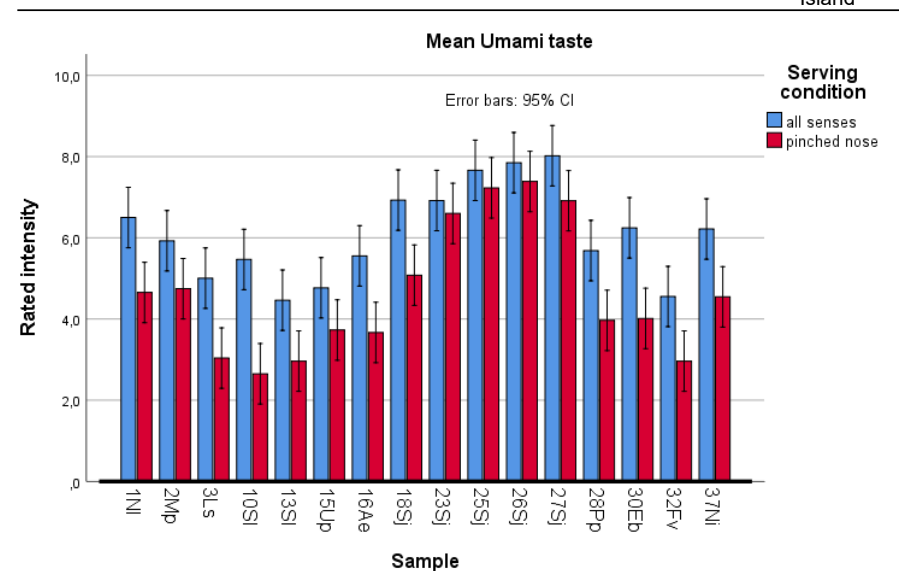

Figure 1: Mean umami taste under the two serving conditions, with confidence intervals $(95 \% \mathrm{Cl})$ as error bars

Table 2: Samples with high umami intensity and low content of glutamate. Showing the aroma compounds that they contain relatively high amounts of

\begin{tabular}{|ll|}
\hline Sample & $\begin{array}{l}\text { Potential candidates for olfactory umami- } \\
\text { enhancement }\end{array}$ \\
$\begin{array}{|ll|}\text { 01NI - Bull kelp (Nereocystis } \\
\text { leutkeana), Bamfield, Vancouver } \\
\text { Island, Canada }\end{array}$ & \\
\hline $\begin{array}{l}\text { 37Ni - Bull kelp salt (Nereocystis } \\
\text { leutkeana) Bamfield, Vancouver } \\
\text { Island, Canada }\end{array}$ & (E)-2-Nonenal; (E)-2-Octenolanol; 2-Butenal; Octanal; \\
\hline $\begin{array}{l}\text { 30Eb - Arame (Eisenia bicyclis), } \\
\text { Chiba prefecture, Japan }\end{array}$ & Trimethylamine; 3-Methylnutanal \\
\hline
\end{tabular}

